\begin{tabular}{|l|l|} 
REVISTA Revista Educación \\
ISSN: 0379-7082 \\
ISSN: 2215-2644 \\
revedu@gmail.com \\
Universidad de Costa Rica \\
Costa Rica
\end{tabular}

\title{
Diagnóstico sobre la comprensión lectora de estudiantes normalistas
}

Ríos Higuera, Selenne; Espinoza Cid, Rosa Ascensión

Diagnóstico sobre la comprensión lectora de estudiantes normalistas

Revista Educación, vol. 43, núm. 2, 2019

Universidad de Costa Rica, Costa Rica

Disponible en: http://www.redalyc.org/articulo.oa?id=44058158046

Esta obra está bajo una Licencia Creative Commons Atribución-NoComercial-SinDerivar 3.0 Internacional. 


\title{
Diagnóstico sobre la comprensión lectora de estudiantes normalistas
}

\author{
Assessing Reading Comprehension Skills in Student Teachers \\ Selenne Rios Higuera \\ Escuela Normal Superior de Hermosillo, Hermosillo, \\ México \\ selennerioshiguera@gmail.com \\ (iD http://orcid.org/0000-0002-6379-8334 \\ Rosa Ascensión Espinoza Cid \\ \#Escuela Normal Superior de Hermosillo, Hermosillo, \\ México \\ rosa_espinoza@hotmail.com \\ iD http://orcid.org/0000-0003-1327-5364
}

Redalyc: http://www.redalyc.org/articulo.oa?id=44058158046

Recepción: 21 Enero 2019

Aprobación: 28 Junio 2019

\section{RESUMEN:}

La formación de docentes de educación secundaria requiere desarrollar un perfil de egreso con habilidades intelectuales específicas, una de ellas es la comprensión lectora. Por esta razón, es de suma importancia reflexionar sobre el análisis de las competencias lectoras de las y los futuros docentes. El estudio que sustenta el presente documento tiene como finalidad efectuar un diagnóstico de la comprensión lectora de estudiantes normalistas. Para lograr lo anterior, se aplicó una prueba diagnóstica conformada por un texto cuya temática es la importancia de los medios de comunicación y su relación con la enseñanza. La lectura sirvió como base para responder doce reactivos con los cuales se exploran tres niveles de comprensión de textos: 1) literal, 2) inferencial y 3) analógico. En esta investigación participaron 56 estudiantes de la Licenciatura en Educación Secundaria de las especialidades de inglés y matemáticas de una Escuela Normal Superior del noroeste de México. Los resultados muestran que la mayoría de las y los estudiantes presentaron dificultades considerables en los reactivos de los niveles literal y analógico. El estudio permite identificar algunas de las dificultades que tiene el estudiantado normalista con respecto a los procesos de comprensión lectora, así como también señala la necesidad de reforzar las prácticas docentes que promuevan el desarrollo de la comprensión lectora.

Palabras ClaVE: Comprensión lectora, Formación docente, Estudiantes normalistas.

\section{Abstract:}

Education majors training to become high school teachers must possess good reading comprehension skills. It is, therefore, necessary to be able to gauge this skill among future teachers. This objective of this study was to test current reading comprehension skills among a group of student teachers through a test involving a text about the importance of Media in teaching, followed by twelve comprehension questions. The questions explored three areas of reading comprehension: 1) literal, 2) inferential and 3) analogical. The sample group included 56 Education Majors specializing in High School English and Mathematics at the Escuela Normal Superior in Northwest Mexico. Based on the data collected, students had the most difficulties with literal and critical questions. The importance of this study is that it helps identify challenges faced by undergraduate students in this area at this institution and emphasizes the need to foster the development of reading comprehension skills.

KEYWORDs: Reading Comprehension, Teacher Training, Student Teachers.

\section{INTRODUCCIÓN}

La formación de docentes de educación secundaria requiere desarrollar un perfil de egreso con habilidades intelectuales específicas; una de ellas es la comprensión lectora. Por esta razón, es de suma importancia el análisis de las competencias lectoras de las y los futuros docentes. La comprensión lectora es una herramienta 
necesaria para tener acceso al aprendizaje (Cassany, Luna y Sanz, 2000; Solé, 1997), así como para transmitir conocimientos (García, Martín, Luque y Santamaría, 1996).

En los últimos años, el personal docente de universidades se encuentra preocupado por los bajos niveles de comprensión lectora que posee el alumnado (Echevarría, 2006). A pesar de la necesidad de que el estudiantado universitario desarrolle habilidades de comprensión lectora, el profesorado de nivel superior asume que llegan a las aulas con dichas habilidades, por lo que pocas veces diseñan actividades específicas para trabajarlas, lo cual contribuye al estancamiento del estudiantado en un nivel de comprensión pobre. De hecho, Vidal y Manríquez (2016) consideran un desacierto por parte de las instituciones universitarias asumir que el alumnado que ingresa a este nivel superior conoce la cultura académica a la cual se integrará, y que sabe tanto analizar cómo poner en práctica lo que lee. En la Escuela Normal Superior, contexto donde se desarrolló el presente estudio, la baja comprensión lectora se evidencia en los trabajos de clase entregados por estudiantes normalistas (resúmenes, organizadores gráficos, ensayos), lo mismo que en sus informes de proyectos de investigación, lo que ha sido tema de discusión en reuniones de academia dentro de la institución.

La comprensión lectora representa uno de los pilares en la formación inicial de quienes serán docentes. A fin de tener una visión general sobre los esfuerzos que se han llevado a cabo en otros contextos para diagnosticar la comprensión lectora en instituciones de nivel superior, se hizo una indagación sobre investigaciones previamente ejecutadas cuya temática fuese similar a la aquí presentada. Se localizaron investigaciones que departen acerca de la comprensión lectora en educación superior, donde se destacan áreas de oportunidad entre las y los estudiantes de ese nivel educativo.

Debido a los resultados de dichas investigaciones, se considera necesario tener un diagnóstico del nivel de comprensión lectora en el que se encuentra el estudiantado de la Escuela Normal Superior en cuestión. De esta forma se pueden tener las bases para el diseño de acciones las cuales busquen la mejora de esta habilidad en las y los futuros docentes, pues, como se mencionó anteriormente, esta es fundamental para ser capaces de aprender y, más aún, de enseñar (Cassany, Luna y Sanz, 2000; García, Martín, Luque y Santamaría, 1996; Solé, 1997). Es por ello que el objetivo de este artículo es presentar los resultados del diagnóstico de comprensión lectora de estudiantes normalistas llevado a cabo en una Escuela Normal Superior, con el fin de desarrollar un análisis que lleve hacia la reflexión sobre la formación de las y los futuros docentes con respecto al desarrollo de la comprensión lectora.

\section{Antecedentes prácticos}

En Latinoamérica, Llanos (2013) señala en su estudio que en Perú los resultados sobre comprensión de lectura continúan siendo deficientes pese a que se han promovido diferentes acciones para contrarrestar este rezago. Esta investigación buscó determinar el nivel de comprensión lectora del alumnado del primer ciclo en siete escuelas profesionales de la Universidad Católica Santo Toribio de Mogrovejo de Chiclayo, según las dimensiones literal e inferencial. Los resultados arrojaron que quienes participaron en el estudio, en su mayoría, contaban con un nivel de dominio básico con respecto a su capacidad de comprensión, análisis e interpretación de textos. Asimismo, la investigación de Llanos (2013) mostró que las y los estudiantes preferían buscar datos en el texto por encima de inferir, habilidad que les demandaría una mayor exigencia de razonamiento.

Por otro lado, en Colombia, Calderón y Quijano (2010) llevaron a cabo un estudio cuyo objetivo principal era identificar las características y habilidades de comprensión lectora en estudiantes de Psicología y Derecho en sus primeros semestres. Los resultados mostraron que las personas participantes se encontraban en un nivel literal de comprensión de textos, esto quiere decir que eran capaces de extraer información específica, pero no de efectuar inferencias a partir de la información contenida en el texto.

En España, Echevarría y Gastón (2002) elaboraron una investigación para analizar los niveles de comprensión de textos expositivo-argumentativos de cierta dificultad por parte de estudiantes que cursaban 
el primer año de estudios universitarios. Según las autoras, los resultados mostraron que los problemas de comprensión lectora que sobresalían eran la no jerarquización de información relevante y la no captación de la intención de la persona autora. Ambas investigadoras consideran que esto puede deberse a que ser capaz de seleccionar ideas principales requiere que la persona lectora se remita al texto y al propósito del autor o autora; sin embargo, resaltan también que es notorio que lectores sin experiencia seleccionen ideas dejándose influenciar por sus creencias y conocimientos previos.

\section{MARco TEÓRICo}

\section{El concepto de leer}

Carrasco (2003, citado por Monroy y Gómez, 2009) señala que hay una diferencia entre aprender a leer y leer. Según esta autora, señalan Monroy y Gómez (2009), lo primero es lo que enseña la escuela, y consiste en reconocer un sistema de representaciones escritas, sin que ello implique que cada estudiante aprenda a comprender. Lo anterior remite a la experiencia que tradicionalmente se ha experimentado en los primeros años de escuela, donde la lectura se evaluaba con relación a la dicción y fluidez al leer en voz alta. Sin embargo, la comprensión lectora es un proceso que exige más que solo aprender a decodificar palabras o a pronunciarlas bien.

En primer término, comprender un texto implica formarse una interpretación del mensaje que se ha transmitido, y es necesario que quien lee tenga objetivos o intenciones (Nuttall, 1996; Solé, 1997). En segundo término, es necesario que, durante el proceso de lectura, se hagan predicciones e inferencias, con apoyo en la información que da el texto y en el propio bagaje, el cual se refiere al conocimiento que ya posee el lector o la lectora (Solé, 1997). Relacionado con lo anterior, la organización de conocimiento (o esquemas) también juegan un papel importante, pues quien lee interpreta basándose en los esquemas que posee (Nuttall, 1996).

No obstante, decodificar un mensaje no es lo que interesa al profesorado, toda vez que la mera decodificación no vuelve a las personas funcionales. Saber leer va más allá de la decodificación; saber leer implica comprender (Nuttall, 1996; Solé, 1997; Ur, 1991). De hecho, Ur (1991) señala que leer significa leer y comprender. Por tanto, señala la autora, si una persona que es capaz de leer no entiende lo que leyó, no sabe leer. Si bien es cierto que Ur (1991) asevera esto respecto de la persona aprendiz de una lengua extranjera, también resulta aplicable para quien lee un texto en una primera lengua. Para la presente investigación, este es justo el concepto de lectura que interesa. Es decir, se trata de un concepto que implique más que el solo hecho de reconocer palabras que quizá carezcan de significado para el o la estudiante; se necesita un concepto que permita a la persona el análisis y a la reflexión de lo que lee, permitiéndole relacionar esos nuevos conocimientos con otros que ya posee para así modificar sus modelos mentales o crear nuevos.

\section{La comprensión lectora: un proceso interactivo}

Algunas personas autoras se refieren a la lectura como una habilidad pasiva, donde el lector está inactivo, únicamente recibiendo información. Sin embargo, esta visión de un rol pasivo que se tiene de la persona lectora es errónea puesto que para leer se ejecutan muchas operaciones complejas y laboriosas, aunque no sean observables (Cassany et ál.., 2000).

En complemento de lo ya señalado por Cassany et ál.. (2000), Nuttall (1996) argumenta que la persona lectora se involucra activamente en su intento por obtener el significado del texto que lee. Desde esta perspectiva, la persona lectora está activa al leer un texto para localizar un significado. Más aún, hay una 
interacción entre quien lee y el texto que toma lugar en este complejo proceso que es la comprensión lectora (Nuttall, 1996; Solé, 1997).

¿Qué significa que el lector o la lectora procesen activamente el texto? Aquí es donde cobran relevancia dos tipos de procesos: el modelo ascendente (bottom up) y el descendente (top down) (Nuttall, 1996; Richard, 1996; Solé, 1997). En el primero, la persona lectora procesa las letras, luego continúa con las palabras, lo cual le permite seguir subiendo de nivel para procesar frases, oraciones, etc. Es decir, va escalando los niveles de abajo hacia arriba para poder llegar a la comprensión del texto. Por lo tanto, las propuestas de enseñanza desde este modelo jerárquico confieren notable importancia al proceso de decodificación (letras, palabras, frases, etc.).

En el segundo modelo jerárquico, el modelo descendente, quien lee se enfoca en utilizar sus conocimientos previos y sus recursos cognitivos para establecer anticipaciones sobre el texto. Es decir, el lector o la lectora no parte de las letras, palabras o frases para construir su interpretación, sino de las hipótesis y anticipaciones que ha elaborado con antelación sobre el texto y, de esta forma, procesa el texto para verificarlas. En otras palabras, en este caso quien lee también escala niveles, pero de arriba hacia abajo. Las propuestas de enseñanza basadas en este modelo enfatizan el reconocimiento global de las palabras.

El modelo interactivo del proceso de lectura supone que el lector o la lectora procesan la información con el empleo ambos modelos jerárquicos. De este modo, quien hace lectura parte de letras, palabras, frases, etcétera, para formarse hipótesis y anticipaciones que más tarde habrá de verificar. Puesto de otra forma, el lector o la lectora utiliza de manera simultánea los procesos de orden ascendente y de orden descendente para construir la interpretación de un texto. Por lo tanto, para poder construir una interpretación, quien lee debe hacer un esfuerzo cognitivo durante la lectura y es ahí cuando se habla de una persona lectora activa (Solé, 1997).

Los planteamientos anteriores, entonces, deberían de llevar a las y los docentes, incluso en nivel superior, a reflexionar sobre qué tanto se promueven en las y los futuros profesionistas las estrategias de lectura. De esta forma, dichas estrategias permitirán que se construyan interpretaciones de los textos haciendo uso de ambos modelos de procesamiento de la información.

\section{Los niveles de comprensión lectora}

Es importante analizar la comprensión lectora del estudiantado para adoptar mejoras en las prácticas docentes con relación a esta habilidad. Van Dijk y Kintsch (1983, citado por Vidal y Manríquez, 2016) sostienen que "la comprensión lectora es la capacidad que tienen los individuos para captar e integrar los diferentes elementos de un texto escrito en tres niveles distintivos y progresivos de relaciones" (pp. 96-97).

En referencia a los niveles mencionados en la cita anterior, el nivel uno corresponde al reconocimiento de la microestructura. Es decir, nada más se analiza el significado de las palabras a partir de los enunciados (proposiciones) en los que se encuentran. El nivel dos es donde la persona lectora reconoce el texto como un todo, y es aquí donde identifica proposiciones importantes que le llevan a formarse una idea global del mismo; esto es, el reconocimiento de la macroestructura. Por último, en el nivel tres quien lee construye inferencias para interpretar el texto. Un elemento importante en este nivel son las experiencias previas en las que se basa el lector o la lectora para interpretar, es decir, el reconocimiento de la superestructura.

Las pruebas del Programa Internacional para la Evaluación de los Estudiantes (PISA, por sus siglas en inglés) se dividen en tres tipos partiendo del propósito de la lectura. El primero es el acceso y adquisición de información; este propósito tiene que ver con la habilidad del lector o la lectora para localizar información ligeramente explícita en el texto. El segundo propósito se relaciona con la integración de información, es decir la capacidad de la persona para establecer relaciones entre ideas textuales. Por último, el tercer tipo es el propósito de reflexión-evaluación sobre la información del texto, el cual consiste en la habilidad para analizar de forma crítica el contenido y la forma en la que se presenta la información (Guevara, Guerra, Delgado y Flores, 2015). 
De igual modo, Kabalen y Sánchez (1995) presentan tres niveles de comprensión lectora: literal, inferencial y analógico, los cuales fueron la base para la elaboración del instrumento del presente estudio. En el primer nivel la persona extrae información dada en el texto, pero sin hacer interpretaciones de ningún tipo. En el segundo nivel, establece relaciones más allá del significado literal; es decir, hace inferencias deductivas o inductivas a partir de lo leído. Por último, en el nivel analógico quien lee traslada las relaciones extraídas del texto a otros ámbitos. Kabalen y Sánchez (1995) señalan que

La aplicación de los tres niveles de procesamiento de información durante la lectura propicia el desarrollo progresivo de las habilidades cognitivas requeridas en cada nivel. Esto se consigue a través de la ejercitación sistemática y deliberada, y de la toma de conciencia o reflexión metacognoscitiva de las estrategias aplicadas. La persona que se ejercite en estos niveles logrará consolidarse como un lector crítico, capaz de analizar la información con profundidad. (pp. 5-6)

Estas autoras argumentan también que la lectura crítica debe estar presente durante todo el proceso de lectura. Esto conlleva que la persona lectora utilice su juicio crítico y raciocinio con el fin de

fundamentar sus puntos de vista acerca de la información que extrae de un texto o para identificar falacias de razonamiento, inconsistencias estructurales en la organización de la información que se da, falta de validez, de confiabilidad de la información, etcétera. (Kabalen y Sánchez, 1995, p. 21)

A propósito de lo explicado en la introducción, el instrumento que se utilizó para diagnosticar la comprensión lectora de las y los normalistas se diseñó en consideración de ejercicios como los propuestos por Kabalen y Sánchez (1995), que son utilizados con frecuencia para desarrollar la comprensión lectora en los niveles literal, inferencial y analógico. Estos tres niveles son de sumo interés para el profesorado de la institución donde se llevó a cabo el presente estudio, pues corresponde al tipo de tareas que se le solicita al alumnado y al trabajo final que realizan para poder examinarse y así obtener su título.

\section{Metodología}

La investigación fue descriptiva, con la que se descubren aquellos aspectos de interés para el investigador que luego tendrá que interpretar (Gento, 2004). Asimismo, se adoptó un enfoque mixto en la investigación, con un nivel de profundidad descriptivo. Hernández, Fernández y Baptista (2014) definen el enfoque mixto como un conjunto de "procesos de recolección, análisis y vinculación de datos cuantitativos y cualitativos en un mismo estudio... para resolver un problema” (p. 532). En este sentido, se utilizó como técnica de muestreo no probabilístico el llamado muestreo por conveniencia, la cual permite seleccionar aquellos sujetos próximos y a los que tenga acceso quien desarrolla la investigación, y que acepten ser incluidos en el estudio (Otzen y Manterola, 2017). Esto porque al momento de la aplicación, de un universo de 138 sujetos, se encontraban disponibles un total de 56 estudiantes de la Licenciatura en Educación Secundaria de las especialidades de inglés y matemáticas: 19 estudiantes de cuarto semestre y 17 de octavo semestre de la especialidad de inglés, y 20 estudiantes de cuarto semestre de la especialidad de matemáticas. El margen de error fue de 10\%, con un nivel de confianza del 95\%, en tanto que el rango de edad de los sujetos se ubicó de 19 a 25 años.

\section{El instrumento}

La prueba diagnóstica (ver Apéndice) estuvo conformada por un texto en español acerca de los medios de comunicación y su relación con la enseñanza de Cassany, Luna y Sanz (2000). Se eligió el señalado texto por las razones siguientes:

1. Es uno de los libros utilizados con mayor frecuencia por docentes y estudiantes de la institución para sustentar los trabajos escritos (proyectos formativos, ensayos, resúmenes, entre otros). 
2. En el texto se relaciona con el tema de la educación y, por ende, con la licenciatura que cursaban las y los participantes.

3. El texto no contiene vocabulario altamente especializado, por lo que se le consideró como apto para el perfil de alumnos y alumnas inscritos en esta institución.

El instrumento aplicado contenía 12 reactivos, los cuales estaban agrupados en tres partes. En la primera parte se incluyeron cuatro reactivos para evaluar la comprensión lectora en un nivel literal. En el primer reactivo se solicitó completar un organizador gráfico de cinco conceptos. En el segundo reactivo la consigna era hacer un esquema comparativo. El reactivo tres era una pregunta abierta que requería una lectura literal por parte de las y los estudiantes. Por último, el cuarto reactivo constó de cuatro afirmaciones, de las cuales los sujetos debían seleccionar las discutidas en el texto.

En la segunda parte de la prueba se incluyeron cinco reactivos para evaluar la comprensión inferencial. Continuando con la numeración de la primera parte, los reactivos del cinco al ocho eran preguntas abiertas donde se cuestionaba a las y los participantes sobre la postura de las personas autoras, algunas situaciones hipotéticas y la idea general del texto. El reactivo nueve constaba de cuatro afirmaciones, de las cuales los sujetos debían seleccionar las que se podían inferir a partir del texto.

La tercera parte de la prueba contenía tres reactivos, todos ellos redactados como preguntas abiertas. Esta parte evaluó la comprensión en un nivel analógico, y solicitó al alumnado responder con base en su opinión, autores y teoría. El hecho de que las y los participantes contestaran a partir de los conocimientos relacionados a su especialidad (matemáticas o inglés) no afectaba al momento de evaluar la respuesta por parte de las autoras del estudio, pues la información del texto no estaba relacionada de manera particular con contenido de ninguna de las dos especialidades.

Para validar el instrumento, se efectuaron dos acciones. Así, una vez diseñado el instrumento, se procedió a solicitar una evaluación de este por parte de dos personas expertas en el tema de comprensión lectora, ambas personas fungían como docentes en la institución donde se ejecutó el estudio. Posteriormente, se desarrolló un pilotaje con 15 estudiantes de una universidad inscritos en la Licenciatura en Enseñanza del inglés. Una vez que se analizaron los resultados, se modificó la redacción de las instrucciones y se eliminó uno de los reactivos por considerarse que medía el conocimiento previo y no la comprensión del texto. Dicho reactivo se encontraba en la sección de comprensión inferencial y consistía en solicitar a las y los alumnos inferir el significado de aculturizan, palabra que se mencionaba en el párrafo 5 del texto. El texto no proveía información que permitiera inferir el significado a partir de la lectura; en todo caso, la inferencia tenía que hacerse a partir de conocimientos previos, lo cual daba lugar a un ítem más para la sección de lectura analógica. Sin embargo, por recomendación de las personas expertas, en la sección de comprensión analógica se recomendó incluir ítems donde se evidenciara la capacidad de las y los estudiantes para conectar la lectura con sus conocimientos teóricos previos, y no con conocimientos lingüísticos.

\section{Análisis de los datos}

En el análisis de los datos se utilizó una hoja de cálculo. Al efecto, se contabilizaron las respuestas correctas de los ítems con preguntas cerradas, y se analizaron de forma cualitativa las respuestas de los ítems con preguntas abiertas, se procuró que contestaran la pregunta según las indicaciones.

Es importante destacar que para el análisis de los resultados obtenidos se utilizó la triangulación. Como lo señala Bisquerra (1989, citado por Arias, 2009), la triangulación consiste en la recolección de diversos datos a partir de diversas fuentes de información como son datos estadísticos y conceptos teóricos para luego contrastarlos con los resultados obtenidos a través de la aplicación de los instrumentos. 


\section{Resultados}

Los resultados se presentan de acuerdo con las secciones de la prueba aplicada. Los textos tomados directamente de las respuestas escritas de las y los participantes, aparecen tal y como fueron escritos.

\section{1) Nivel de comprensión lectora literal}

El primer reactivo de la prueba diagnóstica consistía en identificar las funciones de los medios de comunicación mencionadas en el texto. A este respecto, en el reactivo se incluyó un organizador gráfico donde el concepto principal era medios de comunicación, y de ahí se desprendían cinco espacios para cada una de las funciones; es decir, la máxima cantidad de respuestas correctas era cinco. Poco más de la mitad del alumnado (52\%) obtuvo entre 3 y 4 respuestas correctas. Sin embargo, únicamente 4 estudiantes tuvieron cinco respuestas correctas.

En el segundo reactivo, las y los estudiantes debían hacer un esquema comparativo del antes y del hoy con relación a las actividades de ocio y tiempo libre tratados en el texto. La instrucción no especificaba el tipo de esquema que debían ejecutar, pero sí especificaba que debía ser información a partir del texto (ver Apéndice), es decir, el ítem requería una comprensión de lectura literal. En relación al diseño del esquema, de los 56 estudiantes, solamente uno hizo como esquema un mapa mental; el resto de las y los estudiantes hicieron mapas conceptuales o tablas en columnas verticales, a excepción de uno que las hizo horizontales.

A propósito de la información incluida en los esquemas, solo tres estudiantes (uno de octavo semestre de inglés y dos de cuarto semestre de matemáticas) incluyeron en el esquema las seis actividades mencionadas en el antes y las dos actividades mencionadas en el hoy, según el texto. En el caso del estudiante de inglés, este agregó el concepto de redes sociales a la parte del hoy, el cual no se mencionaba en el texto. Casi la mitad de las y los estudiantes (46\%) obtuvo entre 0 y 4 respuestas correctas de 8 . Los y las estudiantes de octavo semestre de inglés y cuarto de matemáticas fueron quienes obtuvieron mejores resultados al elaborar el esquema.

Cabe mencionar que 15 de 56 estudiantes (27\%) mencionaron en sus esquemas información que no venían en el texto. La Tabla 1 muestra las actividades que fueron mencionadas con frecuencia tanto en el concepto de Antes como en el de Hoy (o Después) y que no aparecían en el texto. 
TABLA 1

Actividades de ocio antes y hoy. Comparación de las respuestas de estudiantes y el texto.

\begin{tabular}{|c|c|c|}
\hline & Antes & $\mathrm{Hoy}$ \\
\hline $\begin{array}{l}\text { Respuestas } \\
\text { de las y los } \\
\text { estudiantes }\end{array}$ & $\begin{array}{l}\text { Más } \\
\text { convivencia } \\
\text { Practicar } \\
\text { deportes } \\
\text { Leian más }\end{array}$ & $\begin{array}{l}\text { Visitan redes } \\
\text { sociales } \\
\text { Usan } \\
\text { computadora } \\
\text { Usan celular } \\
\text { Juegan } \\
\text { videojuegos } \\
\text { No hay } \\
\text { comunicación } \\
\text { No hay } \\
\text { convivencia }\end{array}$ \\
\hline $\begin{array}{l}\text { Información } \\
\text { en el texto }\end{array}$ & $\begin{array}{l}\text { Escuchaban } \\
\text { historias de } \\
\text { sus abuelos } \\
\text { Salian a la } \\
\text { calle a jugar } \\
\text { con otros } \\
\text { niños Se } \\
\text { divertian } \\
\text { con juegos } \\
\text { tradicionales } \\
\text { Cantaban } \\
\text { canciones } \\
\text { que habian } \\
\text { aprendido } \\
\text { de los } \\
\text { mayores } \\
\text { Sabian } \\
\text { cuentos, } \\
\text { chistes y } \\
\text { leyendas } \\
\text { Leian } \\
\text { cuentos y } \\
\text { libros } \\
\text { infantiles }\end{array}$ & $\begin{array}{l}\text { Ver } \\
\text { televisión } \\
\text { Escuchar } \\
\text { música }\end{array}$ \\
\hline
\end{tabular}

Fuente: Elaboración propia.

La instrucción en el reactivo decía que a partir del texto se hiciera el esquema del antes y el hoy en relación al ocio y tiempo libre; sin embargo, se observó que las y los estudiantes recurrieron a sus esquemas de conocimiento para interpretar la información. Por ejemplo, en cuanto a las actividades mencionadas en la parte de Antes por parte de estudiantes, a partir de la tabla se interpreta que posiblemente categorizaron las actividades mencionadas en el texto, tal es el caso de la respuesta sobre escuchar historias de los abuelos y salir a la calle a jugar con otros niños, las cuales pueden entrar en la categoría de convivencia. Por otra parte, el estudiantado posiblemente interpretó juegos tradicionales como deportes. Donde mayormente se puede observar información que no se mencionaba en el texto era en la parte de Hoy. En esta parte el tipo de actividades que menciona el alumnado tiene que ver con tecnología que en el año 2000 (año de publicación del texto de la prueba) no era utilizada tan ampliamente por niños, niñas y jóvenes como lo es hoy en día.

García et ál. (1996) citan a Rumelhart (1990) quien, desde la teoría del esquema, señala que hay tres posibles explicaciones de la interpretación incorrecta de un texto: 1) el lector o lectora puede no tener los esquemas apropiados, lo cual le imposibilita para comprender el mensaje; 2) el lector o lectora puede tener los esquemas necesarios pero el escritor o escritora no le proporciona los indicios que necesita; 3) el lector o lectora puede encontrar una interpretación consistente del texto, pero no es la que el escritor o escritora se había propuesto. A partir de los resultados, la tercera explicación de Rumelhart es la que podría contribuir a 
explicar las respuestas de las y los estudiantes. Sin embargo, lo que se debe resaltar aquí es lo que se esperaba como parte de la prueba y no tanto la intención de la persona autora. En otras palabras, el reactivo en cuestión requería de una comprensión lectora literal de información tal y como aparecía en el texto, y no de inferencias a partir de los esquemas de conocimientos del estudiantado.

En el texto se menciona que los medios escritos requieren un esfuerzo un poco mayor por parte de la persona receptora en comparación del esfuerzo requerido por los medios audiovisuales. En el párrafo siguiente las personas autoras señalan que "muchos maestros se quejan de las consecuencias de esta situación” (p. 522), señalando como consecuencias que el alumnado no lee, no estudia y no se esfuerza, y que se pasa el día viendo televisión y escuchando música; incluso detallan que el estudiantado llega a clase con los auriculares puestos. En el reactivo 3, se les pidió que identificaran cuál era la causa de que no leyeran, no estudiaran y no se esforzaran, la cual era que los medios escritos requerían de un mayor esfuerzo por parte de quien lee, según el texto. Este reactivo requería de una comprensión lectora en nivel literal. Solo 10 estudiantes (Tabla 2) identificaron esta información, quienes señalaron que los medios escritos requieren de mayor esfuerzo para su comprensión, y que la proliferación de los medios audiovisuales ha reducido la actitud, las habilidades y ese esfuerzo que se ocupa al recibir información escrita.

TABLA 2

Identificación de causa a partir de consecuencias.

\begin{tabular}{lll}
\hline Especialidad & Semestre & $\begin{array}{l}\text { Estudiantes } \\
\text { que } \\
\text { contestaron } \\
\text { Correctamente }\end{array}$ \\
\hline Inglés & $8^{\circ}$ & 4 \\
Inglés & $4^{\circ}$ & 3 \\
Matemáticas & $4^{\circ}$ & 3 \\
\hline
\end{tabular}

Fuente: Elaboración propia.

El resto de estudiantes indicó como causas algunas consecuencias mencionadas en el texto (principalmente ver televisión y escuchar música) e, incluso refirieron el hecho de llegar con auriculares a clase. También hubo estudiantes que señalaron causas que no aparecían en el texto, tales como que las escuelas no se han adecuado a las nuevas tecnologías y que las y los estudiantes no cuentan con conocimientos previos (Tabla 3). 
TABLA 3

Identificación de causa a partir de consecuencias. Respuestas de estudiantes.

\begin{tabular}{|c|c|}
\hline $\begin{array}{l}\text { Causas } \\
\text { mencionadas } \\
\text { por las y los } \\
\text { estudiantes }\end{array}$ & $\begin{array}{l}\text { Ejemplos de } \\
\text { respuestas de } \\
\text { estudiantes }\end{array}$ \\
\hline $\begin{array}{l}\text { Ver } \\
\text { televisión, } \\
\text { escuchar } \\
\text { música, no } \\
\text { leer, no } \\
\text { estudiar, no } \\
\text { esforzarse }\end{array}$ & $\begin{array}{l}\text { "De pasar } \\
\text { horas frente al } \\
\text { televisor, } \\
\text { ordenador o } \\
\text { escuchando } \\
\text { música en vez } \\
\text { de leer libros." } \\
\text { (Estudiante 47, } \\
\text { comunicación } \\
\text { personal, } 18 \\
\text { abril } \\
\text { 2017) "Porque } \\
\text { pasan la } \\
\text { mayor parte } \\
\text { del tiempo } \\
\text { frente a la } \\
\text { televisión y } \\
\text { escuchando } \\
\text { música." } \\
\text { (Estudiante 45, } \\
\text { comunicación } \\
\text { personal, } 18 \\
\text { abril "Se } \\
\text { 2017) "Se } \\
\text { pasan el dia } \\
\text { delante del } \\
\text { televisor o } \\
\text { escuchando } \\
\text { musica. } \\
\text { Incluso por la } \\
\text { calle y llegan a } \\
\text { clase con los } \\
\text { auriculares } \\
\text { puestos." } \\
\text { (Estudiante 17, } \\
\text { comunicación } \\
\text { personal, 18 } \\
\text { abril } \\
\text { 2017) "Los } \\
\text { alumnos no } \\
\text { leen, no } \\
\text { estudian y no } \\
\text { se esfuerzan." } \\
\text { (Estudiante } 53 \text {, } \\
\text { comunicación } \\
\text { personal, } 18 \\
\text { abril 2017) }\end{array}$ \\
\hline $\begin{array}{l}\text { La escuela } \\
\text { no se ha } \\
\text { adaptado a } \\
\text { las nuevas } \\
\text { tecnologías }\end{array}$ & $\begin{array}{l}\text { "Son porque } \\
\text { aún las } \\
\text { escuelas no se } \\
\text { han } \\
\text { estandarizado } \\
\text { hacia las } \\
\text { nuevas } \\
\text { tecnologias..." } \\
\text { (Estudiante } 37 \text {, } \\
\text { comunicación } \\
\text { personal, } 18 \\
\text { abril 2017) }\end{array}$ \\
\hline $\begin{array}{l}\text { Falta de } \\
\text { conocimientos } \\
\text { previos de } \\
\text { las y los } \\
\text { estudiantes }\end{array}$ & $\begin{array}{l}\text { "Los alumnos } \\
\text { no cuentan } \\
\text { con los } \\
\text { conocimientos } \\
\text { previos que } \\
\text { deben de } \\
\text { poseer..." } \\
\text { (Estudiante } 38 \text {, } \\
\text { comunicación } \\
\text { personal, 18 } \\
\text { abril 2017) }\end{array}$ \\
\hline
\end{tabular}


Fuente: Elaboración propia.

En el caso de estudiantes que sí identificaron la causa a partir de las consecuencias, se observó que agregaron información no especificada en el texto y emitieron juicios de valor (Tabla 4).

TABLA 4

Identificación de causa a partir de consecuencias con juicios de valor. Respuestas de estudiantes.

\begin{tabular}{l}
\hline Ejemplos de \\
respuestas de \\
estudiantes \\
\hline "Los medios \\
auditivos y \\
visuales han \\
hecho una \\
manera fácil \\
y comoda de \\
adquirir \\
información. \\
La cultura \\
escrita pierde \\
importancia \\
frente a los \\
medios \\
visuales. Los \\
medios \\
escritos \\
requieren de \\
mayor \\
esfuerzo por \\
parte del \\
receptor." \\
(Estudiante 7, \\
comunicación \\
personal, 18 \\
abril 2017 ) \\
"Porque el ver \\
tele y videos \\
asi como \\
escuchar \\
musica \\
alimenta al \\
inconsiente y \\
el leer o \\
escribir \\
requiere un \\
poco más de \\
esfuerzo que \\
a ellos les da \\
flojera." \\
(Estudiante \\
37, \\
comunicación \\
personal, 18 \\
abril 2017) \\
\hline
\end{tabular}

Fuente: Elaboración propia.

Por otro lado, los resultados muestran que, en general, hubo estudiantes que no tuvieron dificultad en el ítem donde se les requería identificar entre un conjunto de ideas las que eran discutidas en el texto. El $41 \%$ de estudiantes respondió correctamente obteniendo 4 respuestas correctas de 4 posibles, y el $47 \%$ obtuvo 3 
respuestas correctas. De aquellos y aquellas estudiantes que obtuvieron las 4 respuestas correctas, 13 eran de la especialidad de matemáticas, lo que representa el $65 \%$ del total de estudiantes en esta especialidad.

\section{2) Nivel de comprensión lectora inferencial}

La segunda sección de la prueba consistía en responder a las preguntas haciendo inferencias a partir del texto. Los resultados sugieren que más de la mitad de las y los estudiantes no tuvo dificultad para inferir la postura de las personas autoras con respecto a la información y la comunicación (77\%), y con respecto a los medios de comunicación y su vínculo con la enseñanza (68\%). Sin embargo, en la misma sección de comprensión inferencial se solicitó al alumnado redactar la idea general del texto y solo 9 estudiantes lo hicieron correctamente. De forma similar, Echevarría y Gastón (2002) reportaron un estudio con estudiantes universitarios que presentaron problemas con relación a la captación de las ideas más importantes, donde el 46.6\% captó dos ideas de ocho que las autoras consideraban como básicas, y únicamente un 4.4\% captó más de 6 ideas.

Para explicar estos resultados, las autoras refieren la distinción que Van Dijk hace entre relevancia textual y relevancia contextual. La primera alude a la importancia que un texto tiene en función de su estructura y las señalizaciones de lo que la propia persona autora considera importante, mientras que la segunda, es la importancia que el lector o la lectora atribuye a ciertas ideas de un texto (Echevarría y Gastón, 2002). De esta manera, las autoras argumentan que su muestra estudiantil utilizó la referencia contextual por encima de la textual. A partir de esto, se puede concluir que las personas participantes del presente estudio atribuyeron mayor importancia a la relevancia contextual que a la textual ya que en sus respuestas se pueden ver reflejadas experiencias relacionadas principalmente con la tecnología de la segunda década de los años 2000s que no existía o no era común en la década de finales de los 90s o principios de los 2000s.

El último ítem de esta sección de comprensión lectora en un nivel inferencial mostró resultados similares. El reactivo solicitaba que, de tres oraciones presentadas, identificaran aquellas que podían ser inferidas a partir del texto, las cuales eran dos. Solamente 16 estudiantes (29\%) lograron identificar las dos oraciones que podían ser inferidas a partir de lo que se exponía en el texto.

\section{3) Nivel de comprensión lectora analógico}

En el nivel de comprensión analógico las y los participantes mostraron dificultades para trasladar la información obtenida en el texto hacia otros ámbitos, por ejemplo, la vida real o los conocimientos previos. En esta sección, se les indicó contestar las preguntas a partir de su opinión y argumentando con teoría o autores conocidos cuando así se solicitara.

En el primer ítem de esta sección, se presentó al estudiantado un extracto del texto que contenía un ejemplo de las personas autoras para explicar uno de sus argumentos (ver Apéndice). Se les solicitó a las y los estudiantes que trasladaran la información a un ejemplo concreto, lo cual hicieron correctamente 17 estudiantes (30\%), de los cuales ocho eran de octavo semestre de la especialidad de inglés. Se considera que estos resultados obedecen al hecho de que es en el último año de la carrera (séptimo y octavo semestres) cuando las y los estudiantes desarrollan un proyecto de investigación de manera individual y el cual presentarán para obtener el grado de licenciatura. Al elaborar dicho trabajo, deben hacer relaciones entre teoría y práctica durante el proceso, pues practican por periodos prolongados de trabajo en jornadas de cuatro semanas en las escuelas secundarias; en total, practican cinco jornadas (es decir, 20 semanas) en un ciclo escolar de 10 meses. En cambio, el estudiantado de cuarto semestre elabora proyectos de investigación en equipos cuya temporalización y características establecidas por la institución no permiten una relación de la teoría con la práctica de igual forma que en el séptimo y octavo semestres, lo cual ha dado como resultado 
que no todo el estudiantado de semestres anteriores al séptimo lleguen a hacer este tipo de relaciones teóricoprácticas, pues practican dos jornadas con duración de una semana cada una tanto en tercero como en cuarto semestres.

En el ítem 11 se presentaba a las personas normalistas un extracto del texto acerca de la difusión mundial de los modelos de vida y cómo estos llevan hacia una sociedad de consumo y hegemonía de estados; enseguida, se les pidió mencionar lo que habían comprendido y la opinión que tenían al respecto, y se les solicitó argumentar con teorías o autores. Tres estudiantes citaron a Vygotsky, pero solo uno de ellos relacionó lo dicho por ese autor con la información del extracto, y otro hizo referencia a una de las asignaturas que se les imparten como parte del programa de licenciatura, relacionándolo con el texto leído (Tabla 5). 
TABLA 5

Comprensión y opinión sobre lo leído. Respuestas de estudiantes.

\begin{tabular}{|c|c|}
\hline Observación & $\begin{array}{l}\text { Ejemplos de } \\
\text { respuestas de } \\
\text { estudiantes }\end{array}$ \\
\hline $\begin{array}{l}\text { Cita a } \\
\text { Vygotsky y } \\
\text { lo relaciona } \\
\text { con el texto }\end{array}$ & $\begin{array}{l}\text { Vigotsky } \\
\text { menciona que } \\
\text { el aprendizaje } \\
\text { y } \\
\text { personalidad } \\
\text { del individuo } \\
\text { depende de la } \\
\text { sociedad en } \\
\text { donde se } \\
\text { desarrolle ya } \\
\text { que el medio a } \\
\text { su alrededor } \\
\text { afecta } \\
\text { directamente } \\
\text { en el. Lo que } \\
\text { se difunda a } \\
\text { través de } \\
\text { cualquier } \\
\text { medio de } \\
\text { comunicación } \\
\text { tendrá tan } \\
\text { siquiera un } \\
\text { minimo } \\
\text { impacto en su } \\
\text { receptor. } \\
\text { (Estudiante } \\
26 \text {, } \\
\text { comunicación } \\
\text { personal, } 18 \\
\text { abril } 2017 \text { ) }\end{array}$ \\
\hline $\begin{array}{l}\text { Refiere a } \\
\text { una } \\
\text { asignatura } \\
\text { del } \\
\text { programa } \\
\text { de su } \\
\text { licenciatura }\end{array}$ & $\begin{array}{l}\text { "En la clase de } \\
\text { Desarrollo de } \\
\text { los } \\
\text { Adolescentes, } \\
\text { hemos } \\
\text { realizados } \\
\text { diversas } \\
\text { lecturas sobre } \\
\text { los } \\
\text { estereotipos. } \\
\text { Los cuales, } \\
\text { presentan a la } \\
\text { sociedad el } \\
\text { modelo de lo } \\
\text { que deben } \\
\text { ser. Éstos } \\
\text { afectan } \\
\text { principalmente } \\
\text { a los } \\
\text { adolescentes, } \\
\text { pues son un } \\
\text { público } \\
\text { vulnerable". } \\
\text { (Estudiante } \\
\text { 30, } \\
\text { comunicación } \\
\text { personal, 18 } \\
\text { abril 2017) }\end{array}$ \\
\hline
\end{tabular}

Fuente: Elaboración propia. 
No obstante, en ninguno de los dos casos los estudiantes explican lo que entienden sobre el extracto que se les presenta, solamente se observa en las respuestas que comprendieron el mensaje y que, aunque breve, emitieron su opinión al respecto. Asimismo, 14 estudiantes comprendieron la idea sobre el consumismo, uno más sobre la hegemonía de estados, mientras que solo uno comprendió a qué se refería el autor con ambas ideas. En lo que respecta a la opinión, de los 14 estudiantes que comprendieron la idea sobre el consumismo, tres emitieron opinión pero sin sustentarla con autores o teoría. En cuanto al resto de estudiantes (75\%), sus respuestas reflejan una falta de comprensión de todas las ideas planteadas (la Tabla 6 muestra algunos ejemplos de respuestas).

\section{TABLA 6}

Comprensión de ideas. Ejemplos de respuestas de estudiantes.

\begin{tabular}{l}
\hline "Que es \\
importante \\
difundir los \\
estilos de vida, \\
valores y \\
conductas, para \\
que la sociedad \\
sea mejor \\
positivamente." \\
(Estudiante 6, \\
comunicación \\
personal, 18 \\
abril \\
2017) "Entiendo \\
que los medios \\
de comunicación \\
mueven al \\
mundo, lo que \\
transmiten en \\
ocaciones \\
informa a la \\
sociedad o le \\
muestra \\
diferentes cosas \\
que antes no \\
sabia." \\
Estudiante 4, \\
comunicación \\
personal, 18 \\
abril 2017 "En \\
un mundo \\
utópico, podria \\
ser correcto, \\
pero las \\
interpretaciones \\
que le da cada \\
individuo \\
varian, por lo \\
que no \\
permitiria una \\
hegemoní." \\
(Estudiante 29, \\
comunicación \\
personal, 18 \\
abril 2017) \\
\hline
\end{tabular}

Fuente: Elaboración propia.

Por último, en el ítem 12 se pidió a las y los estudiantes emitir su opinión sobre la idea de las personas autoras de enseñar al alumnado a leer imágenes, interpretar películas y a ser críticos y críticas con los 
programas de radio y televisión. Además, se les solicitó argumentar sus respuestas con teorías o con autores (Tabla 7).

TABLA 7

Opinión sobre idea de autor. Ejemplos de respuestas de estudiantes.

\begin{tabular}{l}
\hline "Alonso en su \\
libro estilos \\
de \\
aprendizaje \\
señala la \\
importancia \\
de utilizar \\
diversos \\
métodos y \\
materiales \\
para enseñar \\
a los \\
discentes." \\
(Estudiante \\
12, \\
comunicación \\
personal, 18 \\
abril 2017) \\
"El PNIEB \\
señala que \\
los alumnos \\
puedan usar \\
la tic's como \\
habilidad. Es \\
importante \\
que \\
reconozcan \\
información \\
que aporte a \\
sus \\
conocimientos \\
y que sus \\
intereses \\
sean para su \\
mejora \\
continua". \\
(Estudiante \\
56, \\
comunicación \\
personal, 18 \\
abril 2017) \\
\hline
\end{tabular}

Fuente: Elaboración propia.

Puede observarse que el estudiante 12 no profundiza en la idea de la cita, y su opinión no se explicita con suficiente claridad; sin embargo, a partir de la cita expuesta por el estudiante, es posible inferir que concuerda en opinión con lo señalado en el texto. Por su parte, el estudiante 56 vincula la información leída en el texto de la prueba con lo señalado en el Programa Nacional de inglés en Educación Básica (PNIEB) de la SEP (2011), programa en el que, al momento de esta investigación, se basaban las y los docentes de secundarias públicas para planificar sus clases y, por consiguiente, se trataba de un programa que utilizaban las personas normalistas para planificar sus jornadas de práctica docente en las secundarias. En ambos casos, no justifican de manera sólida su opinión, es decir con autores o teorías. No obstante, el resto del estudiantado nada más se limitó a externar su opinión. 
El análisis global de los resultados muestra que donde el alumnado presenta mayores dificultades de comprensión es en los niveles literal y analógico. Sin embargo, en el nivel inferencial se observaron dificultades considerables, en particular al redactar la idea general y al identificar ideas que se pueden inferir a partir del texto.

Una posible explicación del bajo desempeño en el nivel literal es que, para comprender un texto en este nivel, es necesario poner en práctica el proceso de lectura ascendente (bottom-up), donde se parte de las estructuras básicas (letras, palabras, oraciones) para comprender el texto; es decir, es un nivel que exige analizar la estructura de la lengua. En cuanto a las dificultades en el nivel analógico, estas quizás pueden obedecer a que las y los estudiantes no logran llevar a cabo el proceso descendente (top-down) de manera adecuada, es decir, dejan de utilizar los conocimientos que ya poseen y de asociarlos con la nueva información.

La falta de objetivos o intenciones al leer a los que Nuttall (1996) y Solé (1997) se refieren puede ser otro de los factores que llevó a los resultados obtenidos, pues ambas autoras señalan que plantearse objetivos o intenciones para leer contribuye a una mejor comprensión lectora, pues quien lee tiene una idea clara de lo que busca en el texto. Aunque el texto elegido tenía una extensión y tema considerados como adecuados para el perfil del estudiantado en la institución donde se llevó a cabo el estudio, el grupo de estudiantes leyó el texto como parte de una prueba solicitada, y no por interés propio. Debido a esto, se considera que no tenían objetivos de lectura guiados por sus propios intereses para que, como señalan Nuttall (1996) y Solé (1997), pudieran tener motivación por comprender el texto.

\section{Conclusiones}

El propósito principal de esta investigación consistió en desarrollar un diagnóstico de la comprensión lectora de estudiantes normalistas, en los niveles literal, inferencial y analógico. El análisis de los resultados permitió identificar áreas de oportunidad en los tres niveles; sin embargo, a partir de los resultados, los mayores problemas se observan en los niveles literal y analógico.

Los resultados de la sección de comprensión lectora en el nivel literal sugieren que las y los estudiantes hicieron uso de sus esquemas de conocimiento para contestar los reactivos. Además, sus respuestas en dicha sección apuntan a que en la lectura se apoyaron de manera sustancial en el proceso descendente (top-down) en vez de apoyarse en el proceso ascendente (bottom-up), a pesar de que este último pertinente si lo que se busca es comprender la organización de un texto y no solo su interpretación.

A propósito del nivel de comprensión inferencial, los resultados sugieren que las y los estudiantes tienen desarrollada la habilidad para inferir la postura de la persona autora con respecto a los puntos que discute. No obstante, se considera que los reactivos de esta sección no requerían de un alto nivel de procesamiento de información, lo cual da pie a un estudio más profundo que corrobore estos resultados.

Una característica observada entre las y los estudiantes normalistas de esta institución es que están dispuestos a emitir su opinión cuando se les solicita, lo cual se vio reflejado en los resultados de la tercera sección de la prueba, correspondiente al nivel analógico. Sin embargo, no sustentaron sus opiniones con bases teóricas o conceptuales, y este punto es una de las principales preocupaciones de las y los docentes de la institución, especialmente de quienes se encargan de impartir clase en el último año de la carrera y de dirigir las tesis de las y los normalistas. Cabe señalar que, en la sección de preguntas de comprensión en nivel analógico, dos de los reactivos especificaban que debían emitir opinión y argumentar con teoría o autores, pero no se especificaba cuáles, pues lo que se pretendía era analizar la capacidad de las y los estudiantes para relacionar sus conocimientos teóricos en ese momento con sus propias opiniones. Tampoco se les solicitó dar respuestas detalladas ni de una extensión precisa.

Por último, el estudiantado no tuvo un tiempo específico para contestar la prueba; el rango de culminación de la misma fue de 20 a 40 minutos. Por tanto, se considera que el tiempo para responder la prueba no afectó su desempeño. Sin embargo, es necesario analizar no únicamente el desempeño del alumnado en cuanto a 
la comprensión lectora sino también el trabajo que ejecutaba el personal docente para desarrollarla en el alumnado a lo largo de los cuatro años de duración de la licenciatura, pues este podría ser un factor que determine su desempeño en pruebas de este tipo.

\section{REFERENCIAS}

Arias, L. M. (2009). Interdisciplinariedad y triangulación en ciencias sociales. Diálogos Revista Electrónica de Historia, 10(1), 120-136. Recuperado de http://www.redalyc.org/pdf/439/43913137005.pdf

Calderón, A. y Quijano, J. (2010). Características de comprensión lectora en estudiantes universitarios. Revista Estudios Socio-Jurídicos, 12(1), 337-364.

Cassany, D., Luna, M. y Sanz, G. (2000). Enseñar lengua. Barcelona: Graó.

Echevarría, M. A. (2006). ¿Enseñar a leer en la universidad? Una intervención para mejorar la comprensión de textos complejos al comienzo de la educación superior. Revista de Psicodidáctica, 11(2), 169-188.

Echevarría, M. A. y Gastón, I. (2002). Dificultades de comprensión lectora en estudiantes universitarios. Implicaciones en el diseño de programas de intervención. Revista de Psicodidáctica, 10, 59-74.

García, J., Martín, J., Luque, J. y Santamaría, C. (1996). Comprensión y adquisición de conocimientos a partir de textos. México, D.F.: Siglo Veintiuno Editores.

Gento, S. (2004). Guia práctica para la investigación en educación. Madrid: Sanz y Torres.

Guevara, Y., Guerra, J., Delgado, U., y Flores, C. (2015). Evaluación de distintos niveles de comprensión lectora en estudiantes mexicanos de psicología. Acta Colombiana De Psicología, 17(2), 113-121. Recuperado de https://b it.ly/2Zg $4 \mathrm{GoD}$

Hernández, R., Fernández, C. y Baptista, P. (2014). Metodología de la investigación. México: McGraw-Hill.

Kabalen, D. N. y Sánchez, M. (1995). La lectura analitico-critica: Un enfoque cognoscitivo para el procesamiento de la información. México: Trillas.

Monroy, J. A. y Gómez, B. E. (2009). Comprensión lectora. Revista Mexicana de Orientación Educativa, 6(16), 37-42.

Nuttall, C. (1996). Teaching Reading Skills in a Foreign Language. Oxford: Macmillan Heinemann.

Llanos, O. (2013). Nivel de comprensión lectora en estudiantes de primer ciclo de carrera universitaria (Tesis de Maestría). Universidad de Piura, Facultad de Ciencias de la Educación, Piura, Perú.

Otzen, T. y Manterola, C. (2017). Técnicas de Muestreo sobre una Población a Estudio. International Journal of Morphology, 35(1), 227-232. doi: https://10.4067/S0717-95022017000100037

Richard, P. (1996). Making It Happen. New York: Longman.

SEP (2011). Programa Nacional de Inglés en Educación Básica. Segunda lengua: Inglés. Fundamentos curriculares. México: SEP.

Solé, I. (1997). Estrategias de lectura. Barcelona: Graó.

Ur, P. (1991). A Course in Language Teaching. Cambridge: Cambridge University Press.

Vidal, D. y Manríquez, L. (2016). El docente como mediador de la comprensión lectora en universitarios. Revista de la Educación Superior, 45(177), 95-118. http://dx.doi.org/10.1016/j.resu.2016.01.009 
Revista Educación, 2019, 43(2), July-December, ISSN: 0379-7082 / 2215-2644

\section{Apéndice}

Instituto de Formación Docente del Estado de Sonora

Escuela Normal Superior de Hermosillo

Prueba diagnóstica de comprensión lectora

\section{MEDIOS DE COMUNICACIÓN ${ }^{1}$}

Introducción

La importancia de los medios de comunicación -en adelante MC- en la sociedad actual es tan decisiva que podemos decir que regulan el progreso y los acontecimientos mundiales los avances tecnológicos han hecho posible la comunicacion a gran escala y a velocidades vertiginosas.

Podemos pensar que la divulgación de cualquier acontecimiento determina su propia realidad. Si algún hecho se mantiene oculto o no llega a divulgarse nunca, es como si no hubiera sucedido jamás. Y si, al contrario alguna cosa no ha pasado o no es cierta pero se divulga por los MC, produce los mismos efectos que si hubiera ocurrido de veras.

\section{3}

Un ejemplo de ello es una anécdota muy conocida: en el año 1938, Orson Welles adaptó "La guerra de los mundos" de H.G. Wells en forma de guión radiofónico, y lo hizo con tal realismo que la noticia de una invasión extraterrestre desencadenó el pánico colectivo y colapsó las vias de salida de la ciudad. Más recientemente, nosotros mismos hemos sido testigos de imágenes falsas y descontextualizadas sobre la guerra del Golfo Pérsico.

La información y la comunicación juegan un papel decisivo en el mantenimiento del orden mundial y en el progreso de la humanidad. El equilibrio mundial, el poder de las grandes potencias o la dependencia de paises menos influyentes se vehiculan y se materializan a través del dominio de los grandes espacios de comunicación.

'Terto de Daniel Casıany, Marta Luan y Glơria Sanz en Enseñ lengua (2000).
Los actuales MC de masas no se limitan a informar o establecer contactos entre realidades lejanas, sino que también convencen, culturizan y aculturizan, de forma explicita, implicita y subliminal. La difusión mundial de modelos de vida, de valores, de conductas, etc. permiten, por ejemplo, la extensión de la sociedad de consumo y la hegemonia de algunos estados. Los MC son, por lo tanto, recursos de poder. Además, hay que tener en cuenta que la información es un producto de consumo más: se compra, se vende y se mueve una parte muy importante de la economía a escala mundial.

6

Los $\mathrm{MC}$ son un espacio y un motor de poder a escala internacional. Por lo tanto, los espacios de comunicación mundial también serán el espacio al que deberản acceder los avances sociales, los conflictos, las opiniones criticas y renovadoras, $y$ tambièn las lenguas, los paises $\mathrm{y}$ las comunidades que quieran hacerse con un lugar en el mundo, mantener unos signos de identidad y no desaparecer como realidad cultural. Conocer los MC, entenderlos y participar en ellos es un requisito imprescindible para el desarrollo, la supervivencia y la modernización de los pueblos.

7

Del mismo modo, el individuo se encuentra indefenso ante el poder de los grandes MC, que por un lado informan $y$ forman, pero por otro le transmiten modelos culturales masificados, lo despersonalizan $y$, al mismo tiempo, intentan instruirle sobre cómo debe organizar su vida, en qué debe gastar su dinero $\mathrm{y}$ a qué debe dedicar su tiempo libre. Vale la pena recordar una famosa $y$ crítica frase de Noam Chomsky: "La propaganda es a la democracia lo que la represión es a la dictadura."

Sólo mediante una actitud crítica y selectiva podremos poner a nuestro servicio las funciones de los MC. Esta actitud critica y selectiva se configura desde los primeros años de enseñanza. La escuela tiene que colaborar en la preparación indispensable de niños y jóvenes para vivir en el mundo presente y futuro, donde

\section{ANEXO 1}


la información, la comunicación y la tecnologia son cada dia más importantes.

Enseñanza y tiempo libre

Los MC actuales no sólo han desplazado a los mensajeros que llevaban las noticias a pie o a los juglares que actuaban de pueblo en pueblo. También han cambiado radicalmente los hábitos $\mathrm{y}$ las actividades de ocio de las personas y, por lo tanto, los tipos de transmisión cultural.

10

Los niños y niñas de antaño escuchaban historias de sus abuelos, salian a la calle a jugar con otros niños, se divertian con juegos tradicionales, cantaban canciones que habian aprendido de los mayores, sabian cuentos, chistes y leyendas, $y$ cuando ya sabian leer, leian cuentos y libros infantiles. En muchas sociedades de los llamados paises subdesarrollados aún es así.

11

En nuestra sociedad, los niños y las niñas pasan la mayor parte de su tiempo libre viendo la televisión o escuchando música. Los MC han invadido el tiempo libre de jóvenes $y$ mayores, $y$ han llegado a todas las clases sociales. Gran parte de la cultura popular oral y escrita se perderá o se transformará totalmente. La escuela no puede ignorar esta realidad.

\section{2}

También debemos tener en cuenta otro fenómeno relacionado con el aprendizaje: el papel del receptor de los MC. Marshall McLuhan (1985. Ver tambièn Carpenter y McLuhan 1960, y Bourdin 1973) elaboró en Norteamérica un estudio crítico sobre la comprensión de $\operatorname{los} \mathrm{MC}$ actuales $\mathrm{y}$, refiriéndose a la televisión postuló que podia llegarse al extremo de que sólo informara al inconsciente, en lugar de estimular el intelecto. ¿Qué consecuencias a largo plazo podria tener el hecho de recibir la información sölo por televisión?

\section{3}

La tecnologia ha hecho que la oferta de medios auditivos y visuales sea cada vez más amplia y diversa; de una manera fácil y cómoda nos llegan informaciones, programa de ocio, publicidad, películas, etc. Recibimos $\mathrm{y}$ consumimos los medios audiovisuales a pesar de que

\section{8}

Nos preocupamos mucho de que los alumnos aprendan a interpretar un escrito o de que sepan analizar una oración, y resulta que ellos pasan mucho más tiempo viendo televisión que leyendo libros. ¿No tendríamos que preocuparnos también de enseñarles a leer imágenes, a interpretar peliculas, a ser críticos con los programas de radio y televisión, además de trabajar aspectos más tradicionales?

\section{9}

Debemos asumir esta realidad $y$ aprovechas las MC en nuestros objetivos de enseñanza. Por una parte, tendremos que utilizar como herramienta didáctica los medios con los que los alumnos estann más familiarizados, porque serán los recursos más motivadores; $y$, por otra, tendremos que buscar nuevas técnicas para animar a los alumnos en la búsqueda de información en medios escritos, en el gusto por la lectura y el desarrollo de las habilidades receptivas con actitudes más activas y reflexivas. mantengamos actitudes mucho más relajadas y pasivas: los podemos recibir acompañados de amigos, nos atraen y nos divierten. La cultura escrita, como comunicación y como ocio, pierde importancia ante la fuerza de la imagen y el sonido.

La actitud, las habilidades y el esfuerzo que representaba recibir todas las informaciones a través de medios escritos (factor en el que se ha basado la educación hasta hace pocos años) se ha visto reducido por la proliferación de los medios audiovisuales. Los medios escritos requieren un esfuerzo un poco mayor por parte del receptor: atención, concentración, un grado de silencio y de soledad, etc.

\section{5}

Muchos maestros se quejan de las consecuencias de esta situación: los alumnos no leen, no estudian, no se esfuerzan. Se pasan el dia delante del televisor o escuchando música. Incluso van por la calle y llegan a clase con los auriculares puestos. ¿Qué podemos hacer?

\section{6}

En otros capitulos hemos comentado que la escuela no tiene el monopolio de la educación de las nuevas. generaciones: esta misión tiene que ser compartida por la familia, las instituciones, la comunidad y, en la sociedad actual, los MC, que tambien deben ser medios educacionales. Mucha gente ha aprendido más a través de periódicos, revistas, cine, radio y televisión que en la misma escuela. Lluch (1989) analiza en profundidad la programación televisiva infantil y lo que los pequeños telespectadores aprenden de ella.

\section{7}

Este fenómeno nos puede llevar a reconsiderar algunos elementos de la educación. Si somos realmente conscientes de la cantidad de horas que nuestros alumnos pasan delante del televisor, del ordenador o escuchando música, en vez de lamentamos de esta situación, tendremos que buscar buenos aliados y nuevas tácticas. Intentar que los jóvenes vean menos la televisión, por decreto, es una batalla perdida, pero podemos hacer que aprendan viendo la televisión y que se interesen por otros medios.
20

Pero aún asi es insuficiente. Hay que educar a los alumnos como receptores críticos y selectivos de los contenidos de los MC. Los niños y los jóvenes son seres absolutamente indefensos ante la publicidad agresiva y la transmisión de valores culturales y morales que se realiza a través de los medios de comunicación más masificados. Debemos darles herramientas para que usen, escojan, entiendan y critiquen los MC

Existe una larga serie de actitudes para desarrollar: configurar los gustos, ser capaces de escoger qué se quiere ver u oir qué no, cómo se puede distribuir el tiempo libre y el tiempo de trabajo, con qué grado de seriedad o credulidad se debe comprender cada programa y cada espacio, etc. El objetivo tendria que ser adquirir criterios, autonomia y una opinión propia ante los contenidos y los discursos ideológicos de los MC. 
Nombre:

Sexo: M__ F__ Edad:___ Especialidad: ___ Semestre:

Se te pide que por favor leas el texto de Cassany sobre los medios de comunicación. Deberás hacer la lectura del texto y responder las preguntas que encontrarás a continuación.

PARTE I Contesta las siguientes preguntas a partir de la información de la lectura.

1. En el párrafo 5, se mencionan varias funciones de los actuales medios de comunicación. Con esa información, completa el siguiente esquema.

2. A partir del texto, haz un esquema comparativo del antes y el hoy en relación a las actividades de ocio al tiempo libre.

3. Según el texto, explica cuál es la causa de que los maestros se quejen de que los alumnos no leen, no estudian y no se esfuerzan.

4. De las siguientes ideas, señala con una ü las que se discuten en el texto.

\begin{tabular}{|l|l|}
\hline a. Los medios \\
de \\
comunicación \\
deben ser \\
aprovechados \\
para la \\
enseñanza. \\
\hline b. Los \\
alumnos \\
deben ser \\
educados para \\
ser críticos y \\
selectivos en \\
relación a la \\
información \\
que ofrecen \\
los medios de \\
comunicación. \\
\hline c. Es \\
necesario que \\
convenzamos \\
a nuestros \\
alumnos de \\
ver menos \\
televisión y \\
pasar menos \\
tiempo frente \\
a sus \\
computadoras. \\
\hline d. La cultura \\
popular oral y \\
escrita se irá \\
transformando \\
o, incluso, \\
podria \\
perderse. \\
\hline
\end{tabular}

PARTE II Contesta las siguientes preguntas haciendo inferencias a partir de la lectura.

5. ¿Qué tan importantes son para el autor la información y la comunicación? ¿Por qué?

6. A partir de lo que expone el autor, ¿qué pasaría con los relatos de cuentos por parte de abuelos o papás? 
7. ¿Qué se puede inferir acerca de la postura del autor respecto a los medios de comunicación y su relación con la enseñanza?

8. En un enunciado, redacta la idea general del texto en su apartado "Enseñanza y tiempo libre".

9. Señala con una ü las ideas que se pueden inferir a partir del texto:

\begin{tabular}{|l|l|}
\hline a. Entre más \\
acceso a la \\
información y & \\
la \\
comunicación \\
tenga un país, \\
mayor será su \\
dominio y \\
poder. \\
\hline b. Los \\
docentes en la \\
actualidad no \\
están \\
preparados \\
para \\
modificar sus \\
métodos de \\
enseñanza \\
adecuándolos \\
a los medios \\
de \\
comunicación. \\
\hline c. La escuela \\
no es el único \\
ambiente en el \\
que se puede \\
aprender. \\
\hline
\end{tabular}

PARTE III Contesta las siguientes preguntas según se te indica.

10. En el párrafo 2, el autor dice “... la divulgación de cualquier acontecimiento determina su propia realidad", y luego da el ejemplo de lo ocurrido en 1938, cuando Orson Welles adaptó "La guerra de los mundos" en forma de guión radiofónico con tanto realismo que la noticia de una invasión extraterrestre desencadenó el pánico colectivo y colapsó las vías de salida de la ciudad.

¿Qué ejemplo darías tú para agregar a la explicación del autor?

11. En el párrafo 5, el autor dice, "La difusión mundial de modelos de vida, de valores, de conductas, etc., permiten, por ejemplo, la extensión de la sociedad de consumo y de la hegemonía de algunos estados".

¿Qué es lo que entiendes con esto? ¿Cuál es tu opinión al respecto? Argumenta con autores y/o teoría.

12. En párrafo 18, el autor habla de enseñar a nuestros alumnos a leer imágenes, interpretar películas y a ser críticos con los programas de radio y televisión. ¿Cuál es tu opinión al respecto? ¿Por qué? Argumenta con autores y/o teoría.

\section{Notas}

1. En el párrafo 5, se mencionan varias funciones de los actuales medios de comunicación. Con esa información, completa el siguiente esquema.

2. A partir del texto, haz un esquema comparativo del antes y el hoy en relación a las actividades de ocio al tiempo libre.

3. Según el texto, explica cuál es la causa de que los maestros se quejen de que los alumnos no leen, no estudian y no se esfuerzan.

4. De las siguientes ideas, señala con una ü las que se discuten en el texto.

6. A partir de lo que expone el autor, ¿qué pasaría con los relatos de cuentos por parte de abuelos o papás? 
8. En un enunciado, redacta la idea general del texto en su apartado "Enseñanza y tiempo libre".

9. Señala con una ü las ideas que se pueden inferir a partir del texto:

10. En el párrafo 2, el autor dice "... la divulgación de cualquier acontecimiento determina su propia realidad”, y luego da el ejemplo de lo ocurrido en 1938, cuando Orson Welles adaptó "La guerra de los mundos” en forma de guión radiofónico con tanto realismo que la noticia de una invasión extraterrestre desencadenó el pánico colectivo y colapsó las vías de salida de la ciudad. ¿Qué ejemplo darías tú para agregar a la explicación del autor?

11. En el párrafo 5, el autor dice, "La difusión mundial de modelos de vida, de valores, de conductas, etc., permiten, por ejemplo, la extensión de la sociedad de consumo y de la hegemonía de algunos estados”. ¿Qué es lo que entiendes con esto? ¿Cuál es tu opinión al respecto? Argumenta con autores y/o teoría.

12. En párrafo 18, el autor habla de enseñar a nuestros alumnos a leer imágenes, interpretar películas y a ser críticos con los programas de radio y televisión. ¿Cuál es tu opinión al respecto? ¿Por qué? Argumenta con autores y/o teoría.

\section{BY-NC-ND}

